\title{
Toward understanding the effect of top predators on ecosystems
} Nicolas Lecomte, Dorothée Ehrich, Rolf A Ims and Nigel G Yoccoz*

\author{
Address: Department of Biology, University of Tromsø, Drammensv 201, N-9037 Tromsø, Norway \\ *Corresponding author: Nigel G Yoccoz (nigel.yoccoz@uit.no) \\ FI000 Biology Reports 2009, I:26 (doi: 10.34I0/BI-26) \\ The electronic version of this article is the complete one and can be found at: http://FI000.com/Reports/Biology/content/I/26
}

\begin{abstract}
To what extent top predators - carnivores at the top of food chains - drive or just respond to ecosystem dynamics is a central, but partially unresolved, question in ecology. In this report, we highlight how different research approaches employed in aquatic and terrestrial ecology may have a bearing on how the role of top predators in ecosystems is perceived.
\end{abstract}

\section{Introduction and context}

Population declines of top predators (TPs), such as sharks, whales, wolves, and raptors $[1,2]$, are among some of the most obvious human impacts on biodiversity of the last few centuries [3-5]. Recent advances in food web modelling emphasize the role of TPs in the maintenance of biodiversity at several trophic levels, with the loss of TPs driving secondary extinctions faster than the loss of species at lower trophic levels $[6,7]$.

Besides the immediate risk of TP extinctions, more general implications may be due to the different functions of TPs in ecosystems. Whereas removal of TPs may have relatively little ecosystem impact when the food webs are bottom-up (or donor) controlled, much stronger impacts are due to instances in which TPs exert strong top-down control on lower trophic levels. Where this occurs, declining TP populations may induce a trophic cascade, which in the worst case could result in a permanent regime shift, in the sense that the structure and functioning of the ecosystem could become irreversibly altered [8-10]. This outcome appears to be likely in models of food webs with few strong trophic interactions [11]. Yet, in other cases, TPs can be involved in reversible transition between alternative ecosystem states (Figure 1).

There has been a long-lasting debate about the role of TPs, and the relative impact of bottom-up and top-down forces in ecosystems (for example [12]). Fundamentally different environmental contexts (in particular, aquatic and terrestrial ecosystems) have been proposed to underlie context dependencies of TP ecosystem functioning. In this report, by insight gained from recent studies, we exemplify how the different approaches favored by terrestrial and aquatic ecologists may affect what we know about the role of TPs in ecosystems.

\section{Major recent advances}

Behavioral food web ecology

The role of behavior has been an important topic in studies focusing on predator-prey interactions and was first investigated in aquatic ecosystems $[13,14]$, although much research was biased toward emphasizing riskaversive prey behavior (reviewed in $[15,16]$ ). However, Lima's plea [15] to 'put back predators in the predatorprey interactions' has been realized recently through studies highlighting how TP hunting mode can contribute to trophic cascades [17]. Further advances in 'behavioral food web ecology' are likely to be brought about by studies that simultaneously consider behavioral interactions between predator and prey $[3,18]$ as well as between multiple predators [19]. Although the role of non-consumptive effects of TPs currently appears to be less emphasized for aquatic food webs than for terrestrial food webs, we are not aware of any reasons why they should be less important [3]. Technical innovations that make behavioral studies more feasible under water are likely to change this state of affairs [20]. 
Figure I. Dynamic model of an ecosystem shifting between alternative states (regimes $I$ and 2)

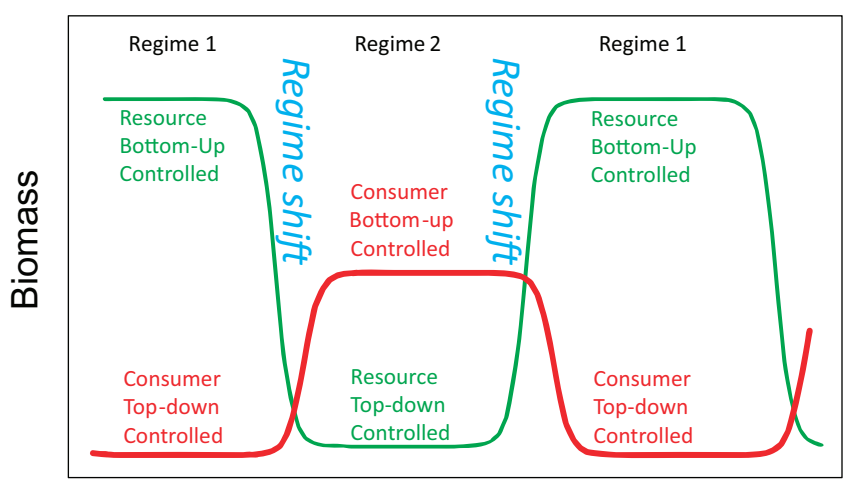

Time

In regime I, the consumer is controlled by a top predator (top-down control) and the resource is controlled by nutrient availability (bottom-up), whereas in regime 2, the resource is controlled by the consumer (topdown) and the consumer is controlled by resource availability (bottom-up). The model is redrawn from [22] based on a marine ecosystem with four trophic levels, although this could be applied to ecosystems with a different number of trophic levels, in both terrestrial and marine environments.

\section{Mesopredator release}

An increasing abundance of smaller predators (mesopredators) when TPs disappear has been documented in both aquatic and terrestrial ecosystems. Such mesopredator releases have major consequences for prey species and primary producers. For instance, the collapse of cod stocks in the north-western Atlantic led to significant changes at several trophic levels, resulting in a transition to an alternative community state [21]. Elmhagen and Rushton [22] demonstrated in a terrestrial ecosystem how the decline in TPs (here, wolf and lynx) favored the increase in abundance of red fox populations, which, in turn, seemed limited by ecosystem productivity. Such joint action of bottom-up and top-down forces means that the concept of mesopredator release needs to be expanded toward an ecosystem-based perspective. In a similar way, Daskalov et al. [23] demonstrated how mesopredator populations can switch between topdown and bottom-up control in alternating regimes in the Black Sea ecosystem. Despite clear similarities across ecosystems in the reactions of mesopredator populations to changes in the abundance of TPs, the flexible size and stage structure in fish populations exacerbate the propensity for shifting trophic structure and dynamic in aquatic ecosystems, as compared with terrestrial ecosystems $[21,24]$.

\section{Predator feedbacks in pulse-driven ecosystems}

Resource pulses (i.e. infrequent, short-term, and largemagnitude booms in productivity at low trophic levels that cascade upward in the trophic system) traditionally have been discussed with reference to terrestrial ecosystems. Although such resource pulses are among the best examples of bottom-up-dominated ecosystem dynamics, recent research has shown how impacts from mobile TPs tracking an asynchronously pulsed resource can dampen pulse amplitude through spatial averaging $[25,26]$. Moreover, diet-switching of generalist TPs is another mechanism driving community dynamics in many pulsed systems, especially through the process of apparent competition between prey sharing the same TP [25]. Despite an initial focus on terrestrial food webs, recent reviews highlight that resource pulses do occur in freshwater and marine ecosystems as well, and that comparative analysis may lead to a novel understanding of this area $[26,27]$.

\section{Data and methods}

Statistical analyses of time series have played a key role in elucidating changes in TP abundance [3], the likely causes of these changes (in particular, the impact of harvesting versus climatic variability [28]) and finally the strength of trophic interactions [29]. Time series of TPs have also played a significant role in the development of statistical time series analysis in general (for example, Canadian lynx). However, in most terrestrial ecosystems, we usually lack information on trophic level dynamics besides TPs; for example, time series of plant and/or herbivore dynamics are nonexistent (except for certain pulse systems for which data on insects or seeds do exist [27]), whereas studies on marine ecosystems can rely on data from many trophic levels, sometimes from phytoplankton all the way to TPs $[9,23]$. The lack of information on other trophic levels obviously limits the inference we can draw regarding the importance of top-down versus bottom-up effects.

Further methodological developments have led to the detection of regime shifts [9]. Examples of such shifts emphasize the role of bottom-up processes and, in particular, climatic control $[8,30]$. On the other hand, interactions between environmental forcing and harvesting of TPs have also been described in marine ecosystems $[9,28]$. Most of the recent evidence for such shifts comes from aquatic ecosystems, although shifts of vegetation states in terrestrial ecosystems do occur (such as the biome shift from steppe to tundra [31] or through desertification [32]), yet remain contentious. 


\section{Future directions}

As evidence accumulates, the simple distinction between bottom-up versus top-down control gets increasingly blurred, such that the same system can even alternate between these two states (Figure 1) [22]. The extent to which marine, freshwater, and terrestrial ecosystems differ with respect to such controls, and which structural parameters determine their strengths, will be reassessed repeatedly as evidence accumulates and valid statistical comparisons accounting for sampling biases are developed. Furthermore, we believe that much more can be learned by comparing these ecosystems within the same theoretical framework [4]. Indeed, although limnic, marine, and terrestrial ecology are often treated as different disciplines, they contribute to a common theory of food web and ecosystem function. Finally, the fact that TPs can link different ecosystems (for example, marine and terrestrial) through migration or subsidies $[33,34]$ testifies for the importance of adopting a broad perspective when studying the role of TPs in ecosystems.

\section{Abbreviation}

$\mathrm{TP}$, top predator.

\section{Competing interests}

The authors declare that they have no competing interests.

\section{Acknowledgements}

This report was funded by the Research Council of Norway through the International Polar Year project 'Arctic Predators' (http://www.arctic-predators.uit.no).

\section{References}

I. Millenium Ecosystem Assessment: Ecosystems and Human WellBeing. Volume 2: Scenarios: Findings of the Scenarios Working Group. Washington, DC: Island Press; 2005.

2. Cury PM, Shin YJ, Planque B, Durant JM, Fromentin JM, KramerSchadt S, Stenseth NC, Travers M, Grimm V: Ecosystem oceanography for global change in fisheries. Trends Ecol Evol 2008, 23:338-46.

3. Heithaus MR, Frid A, Wirsing AJ, Worm B: Predicting ecological consequences of marine top predator declines. Trends Ecol Evol 2008, 23:202-10.

4. Rooney N, McCann K, Gellner G, Moore JC: Structural asymmetry and the stability of diverse food webs. Nature 2006, 442:265-9.

FI000 Factor 8.I Exceptional

Evaluated by Gregor Fussmann 30 Aug 2006, Vlastimil Krivan 19 Jan 2007, David Andow 29 Jan 2007

5. Tylianakis JM, Didham RK, Bascompte J, Wardle DA: Global change and species interactions in terrestrial ecosystems. Ecol Lett 2008, I I:135|-63.
6. Borrvall C, Ebenman B: Early onset of secondary extinctions in ecological communities following the loss of top predators. Ecol Lett 2006, 9:435-42.

FI000 Factor 3.0 Recommended

Evaluated by Andrew Gonzalez 10 May 2006

7. Chesson $P$, Kuang JJ: The interaction between predation and competition. Nature 2008, 456:235-8.

8. Beaugrand G, Edwards M, Brander K, Luczak C, Ibanez F: Causes and projections of abrupt climate-driven ecosystem shifts in the North Atlantic. Ecol Lett 2008, I I: I 157-68.

FI000 Factor 3.0 Recommended

Evaluated by Nigel Yoccoz 22 Oct 2008

9. DeYoung B, Barange M, Beaugrand G, Harris R, Perry RI, Scheffer M, Werner F: Regime shifts in marine ecosystems: detection, prediction and management. Trends Ecol Evol 2008, 23:402-9.

10. Scheffer M, Carpenter S, Foley JA, Folke C, Walker B: Catastrophic shifts in ecosystems. Nature 2001, 413:591-6.

II. Bascompte J, Melián CJ, Sala E: Interaction strength combinations and the overfishing of a marine food web. Proc Natl Acad Sci U S A 2005, 102:5443-7.

FI000 Factor 6.5 Must Read

Evaluated by Jonathan Shurin 06 Apr 2005, Kevin McCann 25 Apr 2008, Fiorenza Micheli II Oct 2005

12. Gripenberg $S$, Roslin $T$ : Up or down in space? Uniting the bottom-up versus top-down paradigm and spatial ecology. Oikos 2007, I 16:181-8.

13. Sih A: Foraging strategies and the avoidance of predation by an aquatic insect, Notonecta hoffmanni. Ecology 1982, 63:786-96.

14. Werner EE, Gilliam JF, Hall DJ, Mittelbach GG: An experimental test of the effects of predation risk on habitat use in fish. Ecology 1983, 64:1540-8.

15. Lima S: Putting predators back into behavioral predator-prey interactions. Trends Ecol Evol 2002, 17:70-5.

16. Quinn JL, Cresswell W: Predator hunting behaviour and prey vulnerability. J Anim Ecol 2004, 73: I43-54.

17. Schmitz OJ: Effects of predator hunting mode on grassland ecosystem function. Science 2008, 319:952-4.

FI000 Factor 3.2 Recommended

Evaluated by Valerie Eviner 2I Feb 2008, Priyanga Amarasekare 29 May 2008

18. Peckarsky BL, Abrams PA, Bolnick DI, Dill LM, Grabowski JH, Luttbeg B, Orrock JL, Peacor SD, Preisser EL, Schmitz OJ, Trussell GC: Revisiting the classics: considering noncomsumptive effects in textbook examples of predator-prey interactions. Ecology 2008, 89:2416-25.

19. Lecomte N, Careau V, Gauthier G, Giroux J-F: Predator behaviour and predation risk in the heterogeneous Arctic environment. J Anim Ecol 2008, 77:439-47.

20. Wilson RP, Vargas FH, Steinfurth A, Riordan P, Ropert-Coudert $Y$, Macdonald, DW: What grounds some birds for life? Movement and diving in the sexually dimorphic Galapagos cormorant. Ecol Monogr 2008, 78:633-52.

21. van Leeuwen A, De Roos AM, Persson L: How cod shapes its world. J Sea Res 2008, 60:89-104.

22. Elmhagen B, Rushton SP: Trophic control of mesopredators in terrestrial ecosystems: top-down or bottom-up? Ecol Lett 2007, 10:197-206.

23. Daskalov GM, Grishin AN, Rodionov S, Mihneva V: Trophic cascades triggered by overfishing reveal possible mechanisms of ecosystem regime shifts. Proc Natl Acad Sci U S A 2007, 104:10518-23.

24. Persson L, Amundsen PA, De Roos AM, Klemetsen A, Knudsen R, Primicerio R: Culling prey promotes predator recovery: alternative states in a whole-lake experiment. Science 2007, 316:1743-6. 
25. Schmidt KA, Ostfeld RS: Numerical and behavioral effects within a pulse-driven system: consequences for shared prey. Ecology 2008, 89:635-46.

26. Yang LH, Bastow JL, Spence KO, Wright AN: What can we learn from resource pulses? Ecology 2008, 89:62I-34.

27. Nowlin WH, Vanni MJ, Yang LH: Comparing resource pulses in aquatic and terrestrial ecosystems. Ecology 2008, 89:647-59.

28. Durant JM, Hjermann DO, Sabarros PS, Stenseth NC: Northeast arctic cod population persistence in the Lofoten-Barents Sea system under fishing. Ecol Appl 2008, 18:662-9.

29. Hjermann DQ, Bogstad B, Eikeset AM, Ottersen G, Gjøsaeter H, Stenseth NC: Food web dynamics affect Northeast Arctic cod recruitment. Proc $R$ Soc B-Biol Sci 2007, 274:66I-9.

30. Trites AW, Miller AJ, Maschner HDG, Alexander MA, Bograd SJ, Calder JA, Capotondi A, Coyle KO, Di Lorenzo E, Finney BP, Gregr EJ, Grosch CE, Hare SR, Hunt GL, Jahncke J, Kachel NB, Kim HJ, Ladd C, Mantua NJ, Marzban C, Maslowski W, Mendelssohn R, Neilson DJ, Okkonen SR, Overland JE, Reedy-Maschner KL, Royer TC, Schwing
FB, Wang JXL, Winship AJ: Bottom-up forcing and the decline of Steller sea lions (Eumetopias jubatas) in Alaska: assessing the ocean climate hypothesis. Fish Oceanogr 2007, 16:46-67.

31. Zimov SA, Chuprynin VI, Oreshko AP, Chapin FS, Reynolds JF, Chapin MC: Steppe-tundra transition: a herbivore-driven biome shift at the end of the Pleistocene. Am Nat 1995, 146:765-94.

32. Scheffer M, Carpenter SR: Catastrophic regime shifts in ecosystems: linking theory to observation. Trends Ecol Evol 2003, 18:648-56.

33. Loreau M, Holt RD: Spatial flows and the regulation of ecosystems. Am Nat 2004, 163:606-15.

34. Maron JL, Estes JA, Croll DA, Danner EM, Elmendorf SC, Buckelew SL: An introduced predator alters Aleutian Island plant communities by thwarting nutrient subsidies. Ecol Monogr 2006, 76:3-24

FI000 Factor 3.0 Recommended

Evaluated by Robert Paine 19 Apr 2006 